\title{
A SINGLE CASE REPORT ON HYPERAMMONEMIA INDUCED BY VALPROATE MONOTHERAPY WITHOUT HEPATIC DYSFUNCTION
}

\author{
C. PRARTHANA SARASWATHI ${ }^{1}$, J. ANU RITA ${ }^{2}$, S. NAMBI ${ }^{3}$
}

Block No C3, Door No-27, Kendriya Vihar Apartments, Sree Balaji Medical College and Hospital, Chrompet, Vellapanchavadi, Chennai-77 Email: prarthana044@yahoo.com

Received: 20 Aug 2016 Revised and Accepted: 14 Feb 2017

\section{ABSTRACT}

Valproate is a commonly used mood stabilizer. One of the important and rare side effects of valproate is hyperammonemia leading to delirium and hepatic encephalopathy. Valproate-induced delirium is commonly mistaken for worsening of manic symptoms or psychosis. We hereby report a case of bipolar affective disorder who was on a therapeutic dose of valproate monotherapy developed altered mental status where we found elevated levels of plasma ammonia which decreased after the discontinuation of valproate and with normal levels of serum valproate, LFT's, EEG and imagings. This case report emphasises on the need to consider plasma ammonia levels in patients with altered mental status receiving valproate in addition to other investigations.

Keywords: Valproate-induced altered mental status, hyperammonemia, plasma ammonia levels

(C) 2017 The Authors. Published by Innovare Academic Sciences Pvt Ltd. This is an open access article under the CC BY license (http://creativecommons.org/licenses/by/4. 0/] DOI: http://dx.doi.org/10.22159/ijpps.2017v9i4.8571

\section{INTRODUCTION}

Valproate is a commonly used mood stabiliser and an anticonvulsant. Valproate-induced delirium due to hyper-ammonemia is a rare adverse effect ascribed to valproate. Often, valproate-induced hyperammonemia occurs when the patient is receiving additional medications like topiramate, has focal neurological deficits or has elevated liver function tests [1-4]. Typically, such hyperammonemia occurs when valproate is initiated. We presented here the case of a valproate-induced delirium due to hyperammonemia in a patient with bipolar disorder when valproate dose was increased.

\section{CASE REPORT}

A 58 y old male with the bipolar affective disorder was on a maintenance dose of valproate $500 \mathrm{mg}$ per day past $3 \mathrm{mo}$ and was increased to 1000 mg per day $4 \mathrm{~d}$ back. He presented with altered mental status, irrelevant and slurred speech, drowsiness, disorientation, difficulty in walking, altered sleep pattern and abdominal discomfort. There was no history of fever, headache, vomiting, hypertension, and diabetes, weakness of limbs, seizures, substance abuse, and head injury prior to the admission. There were no focal deficits and other systems were normal and hemodynamically stable.

All investigations were done to rule out organicity. Blood sugars, serum electrolytes, LFT, RFT, calcium, magnesium, CBC, serum valproic acid, ECG, EEG were found to be normal, but plasma ammonia levels were elevated to $190 \mu$ mole $/ 1$ ( $n=11-32 \mu$ mole $/ 1)$. Valproate was stopped and the patient showed rapid recovery and improvement on the $2^{\text {nd }}$ day with relevant, coherent talking oriented, no drowsiness, and sleep cycle was normal and abdominal discomfort was relieved. Repeat plasma ammonia was done on $5^{\text {th }}$ day and it was decreased to $50 \mu$ mole/l.

\section{DISCUSSION}

Valproate-induced hyperammonemia is a rare condition that typically occurs at the initiation of treatment with valproate, especially in the presence of predisposing factors like use of topiramate. Liver function abnormality is commonly found in such circumstances. In the present case, encephalopathy was present without features of liver dysfunction. The encephalopathy occurred when the dose of valproate was increased from $500 \mathrm{mg}$ per day to $1000 \mathrm{mg}$ per day, still within the therapeutic range. The hyperammonemia could be ascribed to valproate, as increased ammonia levels were present during the phase of altered mental status, and decreased with cessation of valproate.

Valproate-induced hyperammonemia is usually an acute and transient phenomenon that could become life threatening if left untreated [5]. It presents with disorientation, drowsiness, lethargy, gait and sleep disturbances and varying presentation of altered mental status. Focal neurological features have also been described in patients with such a condition. Various mechanisms have been proposed for the development of valproate-induced hyperammonemia. Valproate-induced carnitine deficiency and inhibition of carbamoyl phosphate synthetase enzyme leading to urea cycle disturbances is one of the common mechanisms [6]. Another mechanism proposed is inhibition of the release of glutamine causing increased intracellular osmolality resulting in astrocyte swelling, cerebral oedema and subsequently increased intracranial pressure [7]. Valproate stimulation of renal mitochondria may lead to increased glutamate uptake and release of ammonia in serum [8]. Concomitant use of other drugs like topiramate, aspirin, and cimetidine may increase the non-protein bound fraction of valproate that may lead to hyperammonemia. Comorbid renal failure and hypoalbuminemia may also contribute to the genesis of valproateinduced hyperammonemia.

\section{CONCLUSION}

To conclude, the present case suggests that valproate-induced encephalopathy should be considered when clouding of consciousness and disorientation occurs in the patient on dose increment who is otherwise on stable doses of valproate. Such an encephalopathy can occur without hepatic dysfunction. Prompt discontinuation of valproate may help in rapid correction of the condition, which can be corroborated with monitoring of plasma ammonia levels.

\section{ACKNOWLEDGEMENT}

Authors of the study thank all the colleagues from the department of psychiatry and department of general medicine for supporting and help writing this case report.

\section{CONFLICT OF INTERESTS}

Declared none

\section{REFERENCES}

1. Deutsch SI, Burket JA, Rosse RB. Valproate-induced hyperammonemic encephalopathy and normal liver functions: 
possible synergism with topiramate. Clin Neuropharmacol 2009;32:350-2.

2. McCall M, Bourgeois JA. Valproic acid-induced hyperammonemia: a case report. J Clin Psychopharmacol 2004;24:521-6.

3. Katano H, Fukushima T, Karasawa K, Sugiyama N, Ohkura A, Kamiya K. Primidone-induced hyperammonemic encephalopathy in a patient with cerebral astrocytoma. J Clin Neurosci 2002; 9:79-81.

4. Verma R, Kori P. Valproate-induced encephalopathy with the predominant pancerebellar syndrome. Indian J Pharmacol 2012;44:129-30.

5. Segura-Bruna N, Rodriguez-Campello A, Puente V, Roquer J. Valproate-induced hyperammonemic encephalopathy. Acta Neurol Scand 2006;114:1-7.

6. Oechsner M, Steen C, Sturenburg HJ, Kohlscutterb A. Hyperammonaemic encephalopathy after initiation of valproate therapy in unrecognised ornithine transcarbamylase deficiency. J Neurol Neurosurg Psychiatry 1998;64:680-2.

7. Verrotti A, Trotta D, Morgese D, Chiarelli F. Valproate-induced hyperammonemic encephalopathy. Metab Brain Dis 2002;17:367-73.

8. Gidal BE, Inglese CM, Meyer JF, Pitterle ME, Antonopolous J, Rust RS. Diet-and valproate-induced transient hyperammonemia: effect of l-carnitine. Pediatr Neurol 1997;16:301-5.

How to cite this article

- C Prarthana Saraswathi, J Anu Rita, S Nambi. A single case report on hyperammonemia induced by valproate monotherapy without hepatic dysfunction. Int J Pharm Pharm Sci 2017;9(4):218-219. 